\title{
Russian comparative embryology takes form: a conceptual metamorphosis toward "evo-devo"
}

\author{
Alexander T. Mikhailov \\ Developmental Biology Group, Institute of Health Sciences, University of La Coruña, Campus de Oza, \\ Building “El Fortín”, Las Jubias Str. s/n, La Coruña 15006, Spain
}

\begin{abstract}
SUMMARY
This essay recapitulates major paths followed by the Russian tradition of what we refer to today as evolutionary developmental biology ("evo-devo"). The article addresses several questions regarding the conceptual history of evolutionary embryological thought in its particularly Russian perspective: (1) the assertion by the St. Petersburg academician Wolff regarding the possible connections between environmental modifications during morphogenesis and the "transformation" of species, (2) the discovery of shared "principles" underlying animal development by von Baer, (3) the experimental expression of Baer's principles by Kowalevsky and Mechnikoff, (4) Severtsov's theory of phylembryogenesis, (5) Filatov's approach to the study of evolution using comparative "developmental mechanics", and (6) Shmalgausen's concept of "stabilizing" selection as an attempt to elucidate the evolution of developmental mechanisms. The focus on comparative evolutionary embryology, which was established by Kowalevsky and Mechnikoff, still continues to be popular in present-day "evo-devo" research in Russia.
\end{abstract}

\begin{abstract}
"Fortunately, there are still a few people around who are qualified to know the origins of the sources feeding the river of a particular science. Without these people, our literature was liable to assume the character of the Middle Ages, whose writings contained many claims of which nobody knows what they were based upon."

(Karl Ernst von Baer 1886, p. 280)
\end{abstract}

\section{INTRODUCTION}

Different nations certainly have divergent views on their own scientific tradition, with longstanding consequences for the lines of research followed. Here, I turn to the embryological tradition that lay the ground for evolutionary thought in Russia. This essay should not in any way be regarded as an attempt to review the experimental and theoretical legacy of Russian embryologists and evolutionists in depth. Rather, it is a personal perception of how questions of development and evolution were tackled in both the Czarist Russian and the Soviet (USSR) Empire by scientists of different cultures and backgrounds. Why in Russia? Primarily because "evo-devo" certainly stems from the works and concepts of Karl von Baer who moved to St. Petersburg, where his ideas had a tremendous impact on the development of evolutionary comparative embryology and morphology, especially in Russia. This is evident in the work of A. O. Kowalevsky and I. I. Mechnikoff, who may be regarded as his close followers (Vucinich 1988; Gilbert 2003; Levit 2007). In the early-mid 20th century, this research field had been further explored by A. N. Severtsov, D. P. Filatov, V. S. Kirpichnikov, I. I. Shmalgausen, and their students. 1 These scientists, each in his own way, not only contributed to knowledge of the regularities of development and evolution, but also elucidated the role of adaptive modifications as 
"modifiers" of such regularities. Consequently, here I focus attention on key generalizations which, in my opinion, can be seen as precursors of modern "evo-devo" (Carroll 2005) and "ecoevo-devo" (Gilbert and Epel 2009) concepts.

Conceptualizing the relationship between morphogenesis, variability and the "transformation" of species: the unfinished treatise by Caspar Friedrich Wolff

The history of embryological research in Russia can be traced back to Caspar Friedrich Wolff (1734-1794; Fig. 1). Born in Berlin, Wolff obtained his doctoral degree in medicine (at the University of Halle) with his monograph "Theoria generationis" (1759). (At that time, the term "generation" encompassed studies of embryonic development). This and his other manuscripts made him responsible for the definition of epigenesis that prevailed in Russia since the end of the 18th century (Blyakher 1955; Raykov 1964; Roe 1979; Mikhailov 1997; Dumont 2007; Witt 2008).
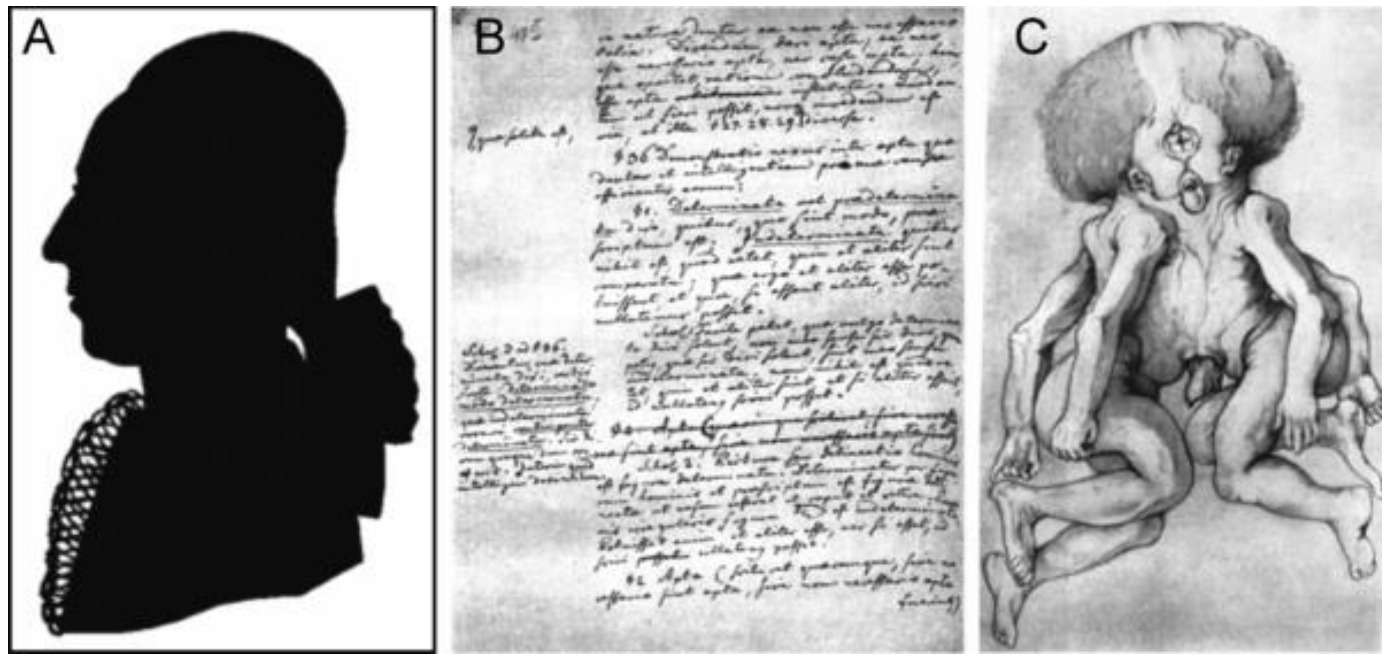

Figure 1. Wolff's manuscript: Objecta Meditationum pro Theoria Monstrorum. (A) A silhouette of Caspar Friedrich Wolff (by F. Anting, 1784). (B) A manuscript page. (C) The drawing of the monstrum VII (from Lukina 1973, modified).

At the age of 30, while still failing to achieve professional recognition in Germany, Wolff accepted a position as Professor of anatomy and physiology (and membership) at the Russian Imperial Academy of Sciences in Saint-Petersburg. It is well known that after becoming an academic at St. Petersburg, Wolff became dedicated to the study of "monsters": conjoined or connected twins preserved in the Kunstkammer (or Museum of Curiosities). Surviving drafts (dated 1778-1783) indicate that Wolff prepared a major treatise on the "theory of monsters," but this work was never finished. Von Baer was very interested in these rough manuscripts and officially recommended them for publication as serial issues (von Baer 1830; quoted in Lukina 1973, p. 268-269). However, in spite of Baer's recommendations, the treatise by Wolff was not published at that time and ultimately fell into obscurity. It was not until 1973, that the collection of Wolff's manuscripts entitled "Objecta Meditationum pro Theoria Monstrorum" was edited (in Latin and Russian) by Tatiana A. Lukina.

In his "theory of monsters," if I interpret his remarks correctly, Wolff attempted to align the mechanisms (forces) of embryonic development (generation) and growth (vegetation) with phenotypic variability, heredity, and the evolution (transformation) of species. Such interpretation of Wolff's manuscripts appears to be complementary to that of Gaissinovitch (1990). 
Wolff supposed that developmental abnormalities could arise by epigenesis rather than preformation. In addition, his observations on "monsters" convinced him that congenital malformations resulting from alterations of normal morphogenesis, keep their species-specific nature (see Lukina 1973, p.113):

“.... any anomalous formation only consists in an increase or decrease in the number of body parts and any other [abnormal] changes stem from this [...]. The parts themselves keep their nature: in humans these parts will always be of a human nature; in the calf, of a bovine nature, and in chickens, chick nature."2

Developmental and congenital abnormalities are interpreted by Wolff as consequences of the so-called "determined" variability, which characterizes a given form/species, and he goes on to conclude that (Ibid, p. 118): “...any organism can change, but only according to a given organism-specific mode of variability." At the same time, Wolff distinguished another type of phenotypic variability in growing organisms, namely, "indeterminate" or "free" variability. The following quotation (Ibid, p. 118) clarifies this definition: “...variations and abnormalities, since they never seem to return to a stable [original] form, but rather they are transformed into a new form, can be named free changes or changes deviating from the norm."

In his discussion of "free" variability phenomena, he stated specifically that (Ibid., p. 119):

“... as a new structure diverges and deviates from the original one by variations and deformities, it diverges and deviates from all other species and, thus, it constantly generates new species, as though drawn from a pool of feasible possibilities, because the change itself achieves such a [degree] that the original trait disappears and a new one is imparted to the structure."
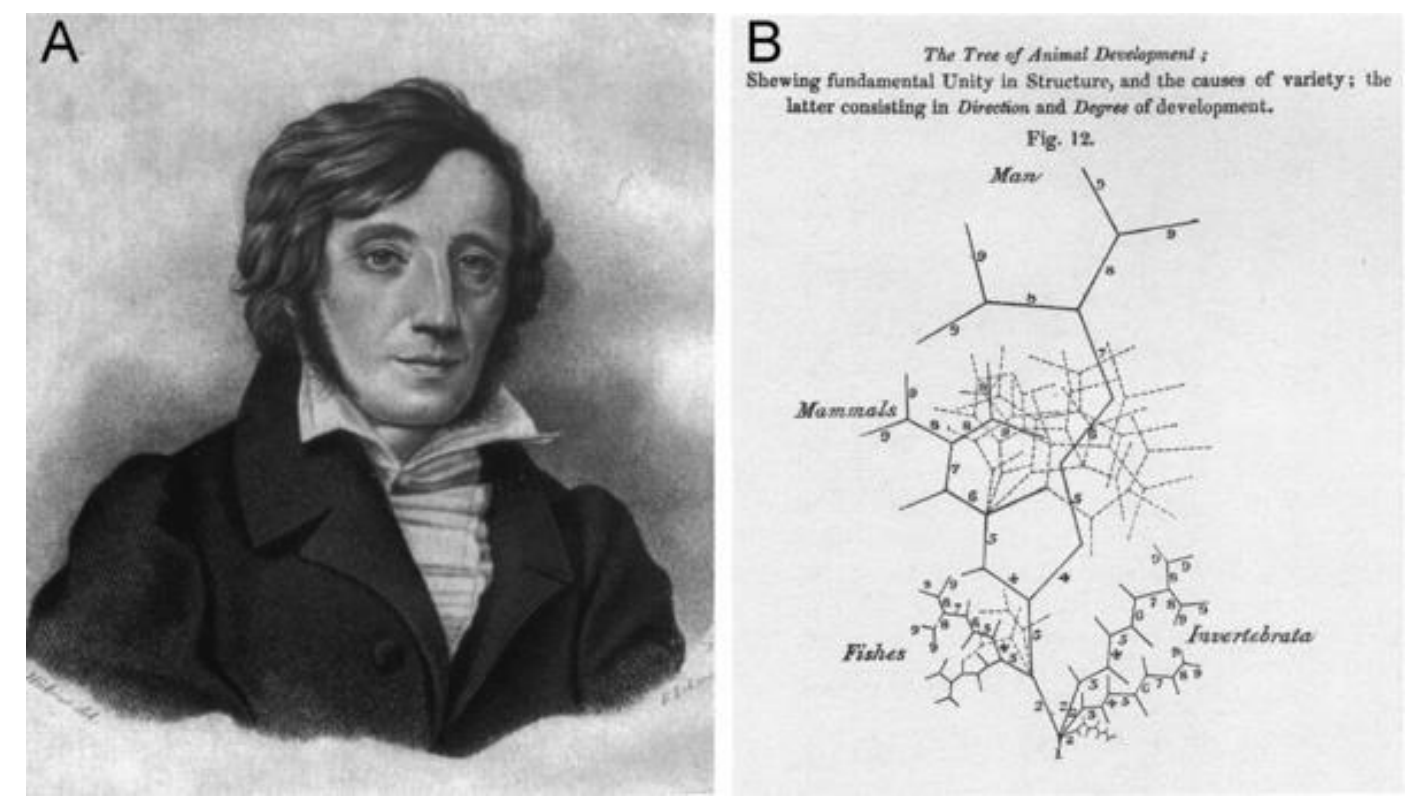

Figure 2. Von Baer's developmental archetypes. (A) Karl Ernst (Maksimovich) von Baer (engraving by F.-L. Leman based upon a portrait by C. Hübner; reproduced with permission from Int. J. Dev. Biol., see Mikhailov 1997). (B) Martin Barry's (1837) sketch of von Baer's theory of the four archetypes. 
If, in line with Wolff's thoughts, "free" variability plays a role in "the transformation" of species, it appears that any new structure, created as the result of such variability, should be transmitted from one generation to another. In Wolff's treatise, there is a special chapter, "The theory of the capacity for transmission to posterity", in which he considers the possible ways and means for heritable transmission. He introduces this chapter with the following statement (Ibid. p. 13):

“... the [generation of] both species-specific and genus-specific traits are determined by vegetation itself; from the point of view of transmission to posterity, these traits should undoubtedly be seen as indispensable and essential for a given type of vegetation [to occur]".

As evident from this quotation, species-specific "vegetation" (growth-patterning process) is held to be mainly responsible for reproducing and transmitting the corresponding phenotype from generation to generation. However, and as discussed by Wolff in his treatise, "vegetation" could be affected by climatic and temperature variables as well as nutrient concentration which could result in the appearance of new phenotypic traits. Could such "acquired" phenotypic variations be transmitted to new generations? The following paragraph from "The Theory of Monsters" reflects consistency in terms of Wolff's thinking about the heredity of phenotypic variations (Ibid., p. 16):

"If a leg, as an example of a discrete organ, were to be amputated over one hundred generations, it, nevertheless, would continue to be constantly re-developed [....]. Similarly, other specific conditions can be observed, where the normal structure of the human body is passed onto posterity only when these defective or specific conditions or characteristics [that make it abnormal] have been generated by external causes and not by changes of the growing substance itself. In the latter case, the changes would be transmitted to posterity. Thus, what becomes heritable is that which has become sufficiently established in the growing substance."

In this sense, Wolff posits that any new trait generated by a correspondingly modified "growing substance" could be hereditable as long as the modified version of such a "growing substance" is transmitted from generation to generation.

Although it is often difficult to adequately interpret the "uncertain" nomenclature or terminology Wolff uses, his assumptions on morphogenesis, phenotypic variability, and heredity may be seen as arguments in favor of the natural "transformation" of species. A successor of Wolff in the St. Petersburg Academy of Sciences, a Russian embryologist of Baltic/German culture, Christian Heinrich Pander (1794-1865) also believed in the "transformation" of species in certain environmental settings (see Schmitt 2005). Further overlapping and interconnections between developmental and "transformist" theories in Russia have been conditioned by comparative embryological research. Arguments in favor of this are presented below.

\section{Discovery of cross-species developmental similarities: empirical generalizations and lessons learned}

The work of Karl Ernst (Maksimovich) von Baer and his followers, A. O. Kowalevsky and I. I. Mechnikoff transformed descriptive developmental anatomy into a specialized branch of comparative embryology, and several "pre-evo-devo" hypotheses were derived from their experimental observations and assumptions.

Von Baer (1792-1876; Fig. 2A) is probably one of the most frequently quoted biologists of the 19th century, not because he was one of the founders of a new perspective on the origin of species as Charles Darwin was, but because he was the first to formulate a concept of embryonic similarity and subsequent progressive divergence across the animal kingdom (see Blyakher 1955; Oppenheimer 1963; Ospovat 1976; Ivanova-Kazas 1992; Richards 1992; Mikhailov 1997; Breidbach and Ghiselin 2007; Braukmann 2008). 
Von Baer, Professor of embryology at Dorpat University (Tartu, Estonia) and member of the St. Petersburg Academy of Sciences, devoted much time over the years to extend Pander's concept of germ-layer formation to all vertebrates. He studied the development of fish, amphibians, reptiles, birds, and mammalians, thus establishing embryology as a comparative science. On the basis of his research, von Baer makes a set of empirical generalizations: (1) embryos of different animals share a germ-layered organization and a consequent embryonic development pattern that progresses through three main stages (primary, histological, and morphological differentiation), (2) the characteristics of type appear earlier in developing embryos than special features so that early embryos of different species are morphologically similar (in some cases indistinguishable) to one another, and (3) the later the stage of development of taxonomically different animals, the less their embryos resemble each other.

The search for developmental similarity and divergence among animals led von Baer to reconsider a classification of the animal kingdom based on archetypes (primary plans) of development. Barry's diagram (see Fig. 2B) illustrates von Baer's theory of relationships among animal developmental archetypes. The root (germ-form) of Baer's developmental tree can be interpreted as a common developmental condition from which any of four archetype pathways can diverge. Indeed, in the fifth scholium, von Baer (1828) notes that any development should pass through a short-time germ condition retaining all potential to follow any of four archetype pathways. In turn, when any of the four major archetype paths are followed, diverse (but related) species can be developed.

As Brian Hall (1997, p. 461) notes, Baer's “interest was comparative, not evolutionary [....]. Von Baer thus provided embryological criteria and an embryological rationale for taxonomic organization." Von Baer himself, by the way, had no doubts that evolution was a fact. Moreover, he believed in a certain degree of parallelism between ontogenetic and phylogenetic processes: the embryos of distantly related species diverge earlier in development than those of closely related species. He did not, however, think that natural selection, alone, was sufficient to cause such evolution. Indeed, in his later years, von Baer writes to the evolutionary biologist Anton Dohrn: " $I$ cannot help but find transmutation probable to a high degree; but I cannot declare Darwin's hypothesis of selection to be sufficient and have believed therefore that transmutation should be explained as a developmental phenomenon" (Baer 1875, p. 77).

However, he suggested that evolution is mediated by its own "internal law of progressive development" and that the "purposefulness" of ontogeny is also a characteristic of phylogeny. Nevertheless, von Baer did strongly disagree with Haeckel's concept that "ontogeny recapitulates phylogeny" stressing that, in spite of a certain similarity during early organogenesis, the embryos of "higher" species are not the same as the adult forms of "lower" animals (see Baer 1828).

Many years later, von Baer's generalization regarding developmental similarity followed by progressive divergence among the taxa was replaced by the developmental hourglass model (Raff 1996) that predicts a "phylotypic stage" (the "waist" of the hourglass), at which point the morphological similarity among embryos of different species within phylum is greatest. Interestingly, in his Autobiography, von Baer (1886) discusses the differences in the early developmental patterns of the fish, frog, and chick embryos, mentioning the heterochronies known today concerning the formation of gill slits. As demonstrated recently, the similarities in gene expression patterns are also greatest during the phylotypic stage in at least Drosophila (Kalinka et al. 2010) and zebrafish (Domazet-Lošo and Tautz 2010).

During the second half of the 19th century (and especially after the publication of Darwin's The Origin of Species in 1859), the relevance of von Baer's developmental generalizations to evolution became clear to A. O. Kowalevsky and I. I. Mechnikoff, who decided to assess relationships across the animal kingdom on the basis of the identification of developmental similarities between embryos of different phyla. Both Kowalevsky and Mechnikoff pioneered evolutionary embryology by carrying out comparative embryological studies on a huge number of invertebrate and vertebrate species (see Vucinich 1988; Mikhailov 1997; Mikhailov and Gilbert 2002). 
Alexander Onufrievich Kowalevsky (Kovalevskii, Kovalevsky; 1840-1901; Fig. 3) became famous for his demonstrations that tunicate larvae have notochords and nervous tissue that are formed in a manner similar to that of lower vertebrates (see Vucinich 1988; Mikhailov and Gilbert 2002; Piliptchuk 2003; Raff and Love 2004; Levit 2007). Impressed by these results, Charles Darwin notes in The Descent of Man:

"...Kovalevskii has lately observed that the larvae of the Ascidians are related to the Vertebrata in their manner of development, in their relative position of the nervous system and in possessing a structure closely like the chorda dorsalis of vertebrate animals $[\ldots . . .$.$] . Kovalevskii writes to me from Naples, that he has now carried$ these observations yet further; and should his results be well established, the whole will form a discovery of the greatest value" (quoted in Vucinich 1988, p. 37).
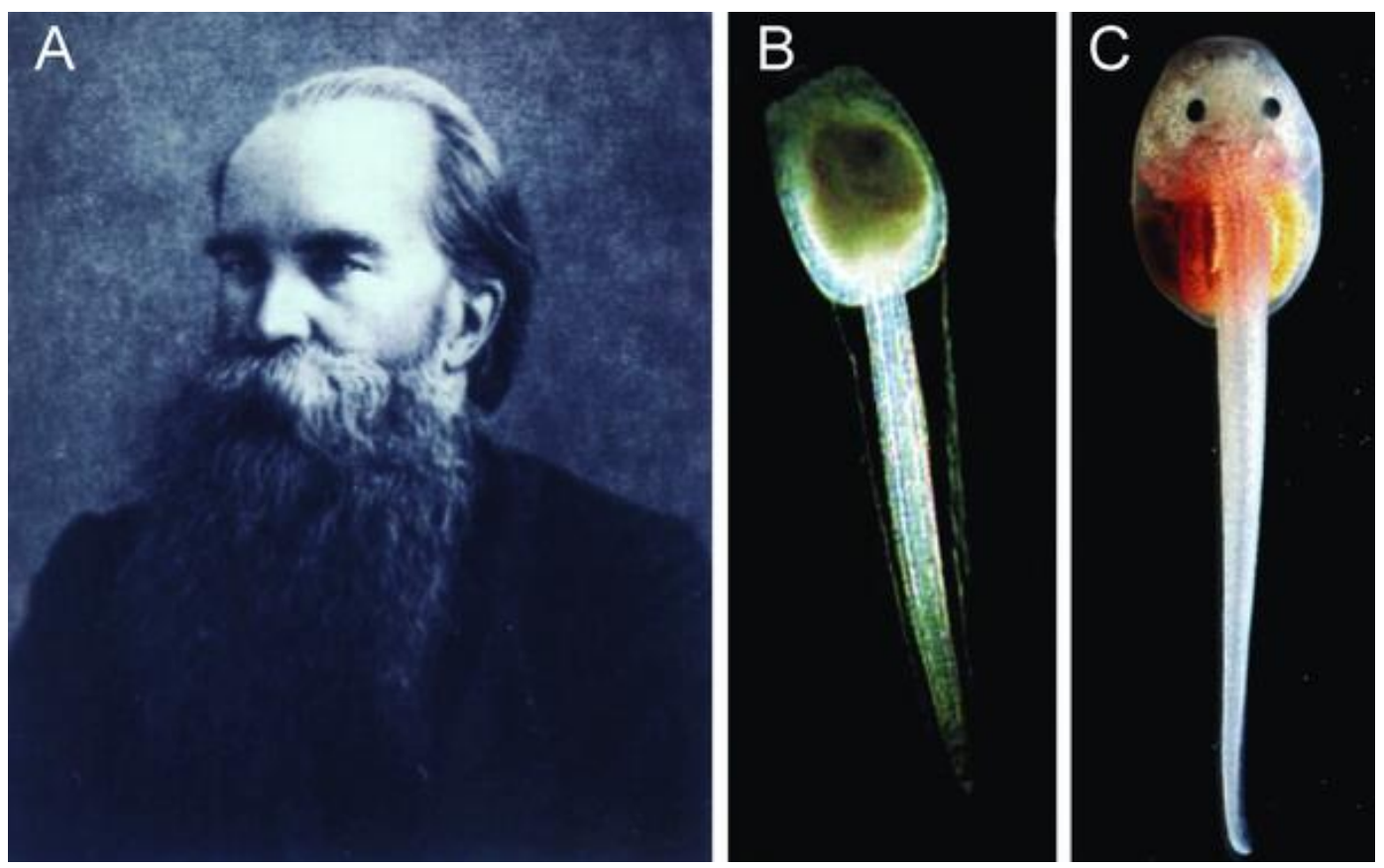

Figure 3. Bringing embryology into evolution. (A) Alexander Onufrievich Kowalevsky (reproduced with permission from Int. J. Dev. Biol., see Mikhailov 1997). (B) A tadpole-shaped tunicate larva (from http://www.corbis.co.in, modified). (C) An amphibian tadpole (photograph courtesy by Dr. John P. Clare/Caudata.com, modified).

The results of Kowalevsky's studies on tunicates were used by Ernst Haeckel as empirical evidence of the ascidian theory of the origin of vertebrates (see Bowler 1996). Kowalevsky, in turn, sometimes resorted to Haeckel's theoretical speculations to interpret his own experimental data. However, to see Kowalevsky only as a provider of experimental data that contributed to Haeckel's theoretical speculations would mean to reduce his contributions to comparative embryological research. It should be stressed, in this regard, that there are different views on Haeckel-Kowalevsky's collaboration. So Brian Hall notes (1999, p. 84-85):

"Theories about possible ancestors of the vertebrates fell into several major camps: insects (Geoffroy, 1818-22), ascidian tadpoles (Kovalevsky, 1867; Garstang, 1928), and annelids (Dohrn, 1875).The two major rival theories, however, pointed to an ascidian or annelid ancestry [.... . Haeckel and Kovalevsky based their theory on embryological evidence; Dohrn and Semper based theirs on adult anatomy." 
However, George Levit (2007, p. 134) presents arguments suggesting that "both Kowalevsky and Metschikoff were either indifferent or even hostile to Haeckel and his theories" and that "Kowalevsky and Haeckel had very different scientific temperaments. Kowalevsky was much more cautious in interpreting empirical data."
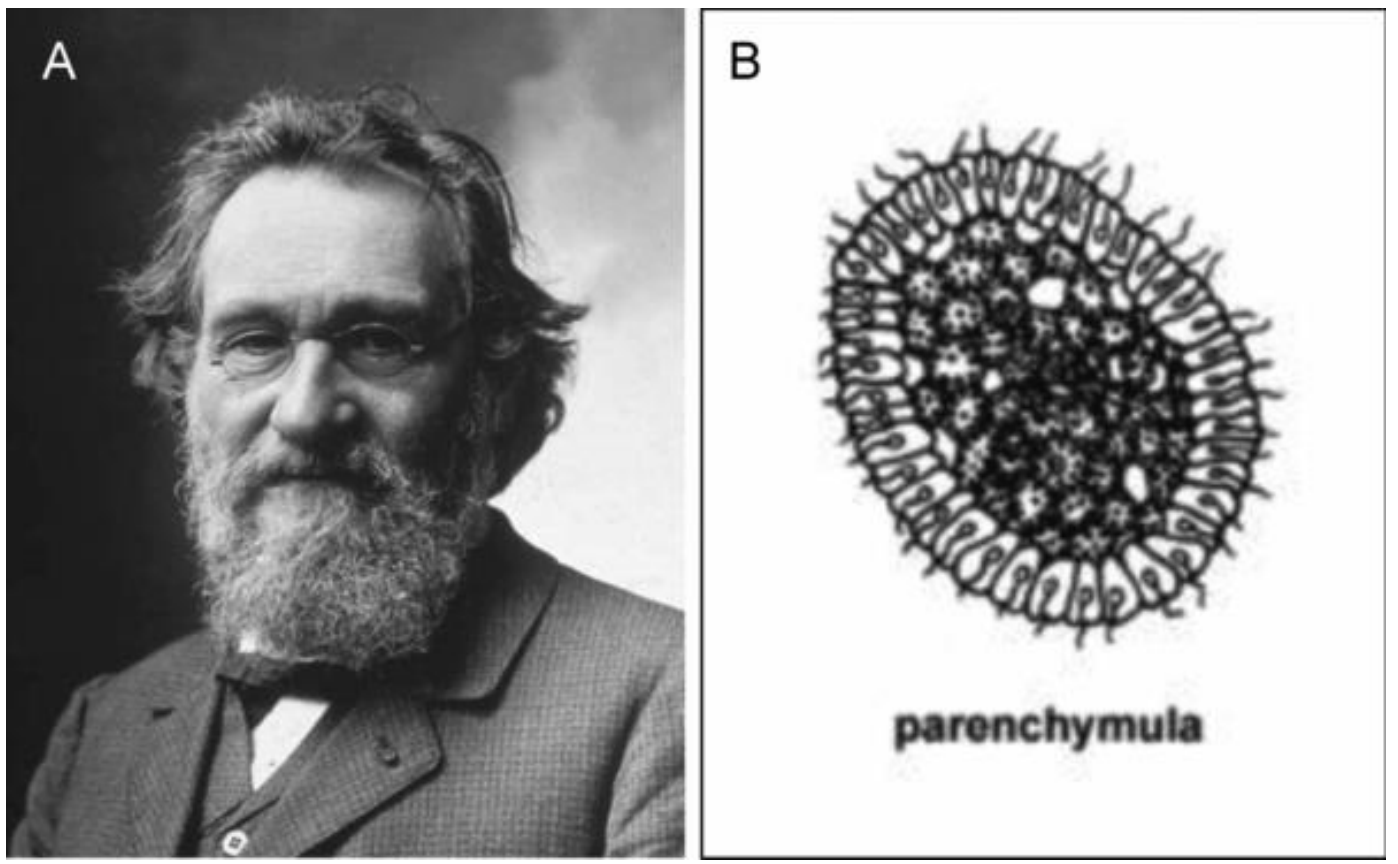

Figure 4. Mechnikoff's "parenchymella" hypothesis. (A) Ilya (Elie) Ilyich Mechnikoff (reproduced with permission from Int. J. Dev. Biol., see Mikhailov 1997). (B) "Parenchymula" - hypothetical ancestor of Metazoa (fragment of the figure from http://www.domotice.us/Demospongiae).

In fact, Kowalevsky showed little interest in theoretical phylogenetic generalizations and limited himself to the following conceptual statement: the greater the similarity between the developmental features/patterns of compared species, the greater could be their phylogenetic affinity. (This turned out to be a prophetic statement). Kowalevsky was an experimentalist of unusual ingenuity: he devoted much time to the careful study of embryos from different phyla to reveal developmental similarities and deduce (paradoxically enough at that time) phylogenetic relationships within the animal kingdom (see Vucinich 1988; Mikhailov 1997; Brauckmann and Gilbert 2004; Raff and Love 2004; Levit 2007).

It has recently been claimed (Raineri 2009) that some of Kowalevsky's interpretations of his own experimental results may be incomplete or even incorrect and that von Baer had doubts about the "reliability" of Kowalevsky's conclusions on the phylogenetic relationship of ascidians and vertebrates. However, it appears to be undervalued or under-recognized that: (1) Kowalevsky was not a pioneer of the annelid theory, as Raineri (2009) states, but he was the first to demonstrate structural and developmental similarities between ascidian and lower-vertebrate larvae; (2) the von Bear 1873 manuscript on ascidians was critical of dilettantes who believed that ascidians could be ancestors of humans, not against Kowalevsky's experimental data (commented in Lukina 1978), and (3) Kowalevsky substantially extended von Baer's empirical generalizations by demonstrating the existence of germ layers and gastrulation processes in both invertebrates and vertebrates (see Mikhailov and Gilbert 2002; Brauckmann and Gilbert 2004). In its abstract form, the work of Kowalevsky on ascidians was arguably the most influential at that time. Kowalevsky's experimental results were greatly appreciated by von Baer, and Kowalevsky was twice (in 1867 and 1870) a recipient of the von Baer-Prize (von Baer himself was a chair of the awarding 
committee). Recent molecular studies strongly suggest that tunicates are the closest living invertebrate relatives of vertebrates (Delsuc et al. 2006) and that the comparative analysis of tunicate and vertebrate gene regulatory networks can clarify the mechanisms of evolution of the chordate body plan (Lemaire et al. 2008).

Illya (Elie) Ilyich Mechnikoff (Metchnikoff; 1845-1916; Fig. 4) is another key figure in Russian evolutionary comparative embryology owing to his studies on the relations between ontogenesis and phylogenesis and for his hypothesis concerning the origin of multicellular animals. He pursued his studies of invertebrates in Naples, where he met and collaborated with Kowalevsky. They became intellectual partners and close friends. By carrying out embryological experiments in light of Pander/von Baer's accounts of germ layers, they revealed the similarity in germ-layer formation between different invertebrate species-but even more importantly, they also discovered the hierarchical nature of germ-layer similarity in phylogenesis. The following quotation from Tauber (2003; p. 898) gives an idea of how they attempted to handle that problem:

"Metchnikoff and Kovalevski had observed a second pattern of embryonic-like formation. Using embryos from sponges, hydroids and lower medusa, they saw cellular "introgression" (unipolar or multi-polar) as the primordial process, and argued that embryonic layers were formed from an initially undifferentiated cellular mass (parenchyma) that arose from cells migrating from the periphery in a less ordered fashion to fill the inner space of the gastrula sphere. Metchnikoff called his hypothetical urmetazoan parenchymella and, because he modeled it on more primitive animals than Haeckel's gastrea, the Russian could claim the phylogenetic priority of introgression as a more ancient mechanism of gastrulation."

In other words, Mechnikoff suggested that the structural organization of his hypothetical first metazoan is similar to that of the parenchymula-a diploblast sponge larva with exterior flagellated cells (Fig. 4B). The modern "Urmetazoon" hypothesis is based on evidence that placozoans (sister group to the sponge-ctenophore-cnidarian clade) are basal relative to all diploblast groups (Schierwater et al. 2009).

Mechnikoff recognized that his contribution had simply been to illuminate evolutionary developmental trends. In this regard, it should be remembered that he opposed the theory that natural selection played a primary role in "external" morphological changes and suggested instead that evolution is underlined by selection processes acting on the level of "internal" cell-cell interactions within developing organisms (Tauber 1990, 2003; Gourko et al. 2000), as well as, on the level of "general" physiological parameters of the organism, such as fecundity and viability (Vucinich 1988).

In the context of previous research by von Baer, the comparative approach accomplished by Kowalevsky and Mechnikoff has founded a new trend in comparative embryology by giving the embryo a place in evolutionary thought. In Russia at that time, the application of this theoretical framework to the study of animal evolution had two traceable consequences: (1) the conversion of comparative-descriptive embryology into comparative evolutionary embryology and (2) a shift toward "pre-evo-devo" concepts based primarily on the phylogenetic modification of ontogeny (i.e., processes of embryogenesis, organogenesis, and growth).

\section{Challenges to understanding the interplay between development and evolution}

In Russia, during the first decades of the 20th century, connections between evolution and development were re-illuminated in the work of founder of the Russian evolutionary morphology Aleksey Nikolaevich Severtsov (Sewertzoff; 1866-1936; Fig. 5A). Severtsov, seen in retrospect as one of the Haeckel's "grandson" students (Hoßfeld and Olsson 2003), has devoted much of his professional life to revising and modifying Haeckel's recapitulation doctrine elaborating his own theory of "phylembryogenesis", according to which evolution is accomplished through morphological changes which can affect ontogenesis at any stage (Adams 1980; Levit et al. 2004; Breidbach and Ghiselin 2007). In 1912, he published the first of a series of his essays, in which he 
treated the relationships between individual development and evolution in a manner still similar to that of Haeckel. Years of subsequent experimental and theoretical efforts gave him grounds for expressing alternative views on development and evolution, which he presented in the book entitled: "The Morphological Regularities of Evolution" (German edition, 1931; revised and expanded Russian edition, 1939).
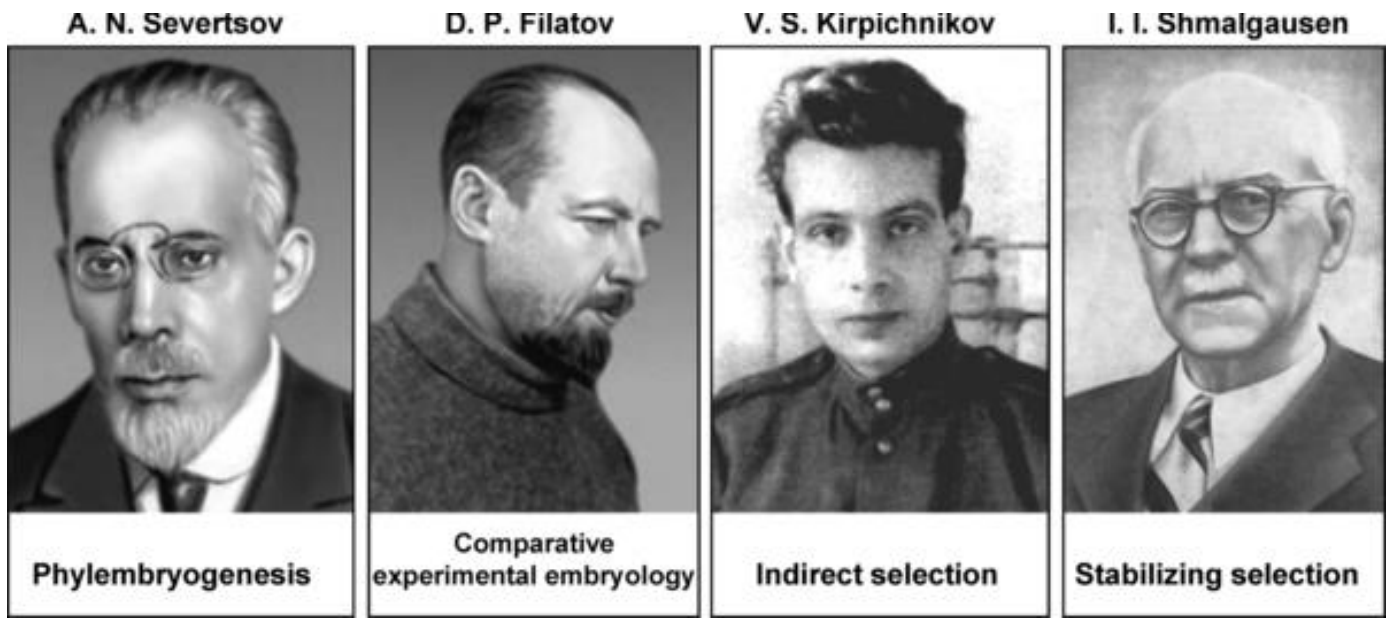

Figure 5. Envisioning mechanisms for evolutionary change. (A) A. N.Severtsov's concept of "phylembryogenesis" (photograph published before 1941; Wikipedia), (B) D. P. Filatov's attempt to study evolution of developmental regularities (photograph reproduced with permission from Int. J. Dev. Biol.; see Dettlaff and Vassetzky, modified), (C) V. S. Kirpichnikov's concept of "indirect" selection (photograph from Golubovsky 2008, modified), and (D) I. I. Shmalgausen's concept of "stabilizing" selection (photograph reproduced with permission from Int. J. Dev. Biol., see Mikhailov and Gorgolyuk 2001, modified).

In the monograph, Severtsov states (1939, p. 478):

"The theory of phylembryogenesis tries to solve the question: how and when the changes, which lead to phylogenetic [transformation] of the adult body organization, appear in the course of individual development [...... It is usually considered that the phylogenetic changes begin with small heritable variations (mutations). Our investigating brings us to the view point of Fritz Müller that the phylogenetic modifications of the [already-formed] organs are paved through alteration of embryonic development of these organs. The various modes of alteration of the ontogeny are: (1) new characters appearing at the end of ontogenesis (anaboly), in such case a true recapitulation or repetition is preserved, (2) a deviation at some inter-mediate stage of ontogeny resulting in recapitulation only of the earlier stages of the [ancestral] history, and (3) changes in the first period of ontogeny (archallaxis), when no traces of recapitulation can remain."

Severtsov suggested that abrupt modifications of early development by "archallaxis" will result in formation of new organs that would be substantially different from those of the organism's progenitors. However, the morphological invariance of the early stages of organogenesis (demonstrated by von Baer) suggested that changing it by "archallaxis" will further disrupt development leading to the death of the embryo (Shmalgausen 1982). Given a modification in the late stages of organogenesis (anaboly), the phylogenetic process could lead to a lengthening of the preexisting (true-recapitulated) paths of development. In addition, and as Shmalgausen (1982, p. 70) comments: "....there is one question this analysis leaves out: What are the causes triggering different [mechanisms] of the phylogenetic organ modification [...]. To answer to this question, a new theory of recapitulation should be elaborated. It can be demonstrated that comparative embryological data alone are insufficient for elaboration of such a theory." 
Severtsov himself understood the deficiencies of his concept of phylembryogenesis (Severtsov 1945, p. 523):

"Of course, one has to recognize that this theory is only a first approximation to a theory of evolution in full. At the present time, we do not have such a complete theory, and we can only guess how it will be created. It seems to us that, in the near future, ecologists, geneticists and embryologists should move forward to generate such a theory, using their own investigations, based on ours."

Severtsov's hopes were justified to a certain extent by the experimental and theoretical efforts of a number of biologists including the experimental embryologist D. P. Filatov, the population geneticist V. S. Kirpichnikov, and the evolutionary biologist I. I. Shmalgausen. ${ }^{3}$

Dmitry Petrovich Filatov (Filatow; 1876-1943; Fig. 5B), a founder of the "mechanics of development" in Russia, at first specialized in descriptive comparative research at the Institute of Comparative Anatomy (1902-1907), but shortly afterward, he turned his attention to the experimental study of development. In particular, he demonstrated that the presumptive inner ear epithelium induces the adjacent mesenchyme to form the auditory capsule. In 1922, Filatov, already an experienced scientist by then, organized the laboratory of developmental mechanics at the Koltzov's Institute of Experimental Biology in Moscow (Dettlaff and Vassetzky 1997). The focus of his research at that time was the analysis of inductive tissue interactions using the lens and limb as experimental models.

Since the late 1930s, Filatov became interested in problems of variability and evolution in morphogenetic interactions and devoted his efforts to the comparative study of similar morphogenetic events in different, as well as in closely related species. In his 1939 book entitled The Comparative-Morphological Trend in Developmental Mechanics, Filatov proposed a novel trend of research in comparative embryology that would be focused on detection of variability in morphogenetic tissue interactions which he called "morphogenetic apparatuses." As Tokindo Okada notes (2000, p. 138):

"The Russian embryologist, Dimitri P. Filatov (1876-1943) must be one of the very few champions to advocate "The Comparative-Morphological Trend in Developmental Mechanics". Unlike W. Roux, who when making comparisons, sought only to confirm a fact previously established on another object, Filatov was concerned mainly with the differences, and he saw in the comparative method a mean for detecting variability in morphogenetic apparatuses."

Filatov suggested that with evolution: (1) the dynamic range, within a given conditional developmental interaction, is increased (Filatov 1939), and (2) not only morphogenetic reciprocal interactions, but also the direct mechanical influence of adjacent parts upon one another may acquire regulatory significance (Filatov 1941). From a broader point of view, Filatov was attempting to integrate, through morphogenetic tissue interactions, the processes of ontogenetic and evolutionary organogenesis; for example, he interpreted the "recapitulation" of notochord rudiments in embryos of higher vertebrates in light of a possible "ancient" morphogenetic role of the notochord in shape-forming processes, as well as in structural support for the embryo (see Dettlaff and Vassetzky 1997). Modern studies demonstrated that evolutionary modifications of embryonic induction processes can lead to significant changes in adult organ morphology (e.g., Yamamoto and Jeffery 2000).

In the 1930s, the population geneticist Valentin Sergeevich Kirpichnikov (1908-1991; Fig. 5C), while working at the Koltzov's Institute of Experimental Biology under the mentorship of S. $\mathrm{S}$. Chetverikov, became interested in the theory of evolution. Kirpichnikov, simultaneously with a zoologist Ephim I. Lukin, identified (on the basis of the analysis of large-scale population data) a marked parallelism in the rate of both environmental and mutational modifications in various geographical subspecies. These results led both researchers to a similar suggestion: organisms respond to acute environmental changes by massive adaptive modifications that could become genetically fixed in geographic races under the corresponding environmental influences. Such a 
process of fixation of environmentally induced modifications was first named as "indirect" (Kirpichnikov 1935), and later on as "coincident" selection that in Kirpichnikov's own words (1947, p. 173), is:

".... the selection of small physiological mutations: they acquire the greatest value in this phenomenon. Such alteration of the basic physiological characters is the result of direct natural selection. Thus the appearance of stable hereditary differences in physiological characters at the earliest stages of divergent evolution finds its explanation. The direct selection of viability through physiological characters in the presence of sharply modified organs leads to the partial fixation of the adaptively modified structures. Therefore such selection happens to be at the same time coincident selection."

Kirpichnikov argued that "coincident" selection of adaptive physiological mutations could result in a certain independence of development from environmentally induced alterations and suggested that "the evolutionary process as a whole is characterized by progressive stabilization of development, particularly in the earlier embryonic stages" (Ibid., p. 173).

In his paper in memory of Kirpichnikov, genetics expert and biology historian Michael D. Golubovsky notes (2008, p. 284):

"R. I. Berg, a well-known evolutionary geneticist [......] underlined that Shmalgausen's concept of stabilizing selection also includes the hypothesis of indirect selection as well as other similar ideas, coincident and organic selection, genetic assimilation, and etc., as particular natural scenarios. Moreover, the fixation of modifications via selection of mutations comes into existence not as a direct consequence of selection of a given trait, but rather as a side-effect of the overall stabilization of traits..."

In fact, Shmalgausen's concept of "stabilizing" selection goes much further than the "coincident" selection hypothesis and is directly related to the mechanisms of adaptive modification of "individual" development in the course of "historical" development (Adams 1988).

The scientific legacy of Ivan Ivanovich Shmalgausen (Schmalhausen; 1884-1963; Fig. 5D) as well as his timeline record has recently been commented in detail (Levit et al. 2006; Levit 2007; Olsson et al. 2010; Vorob'eva 2010). Shmalgausen started his scientific career (as a graduate student from 1902 to 1904) under the guidance of Severtsov. It is not, therefore, surprising that until the mid-1930 Shmalgausen's methodological and theoretical approach resembled that of his teacher (Adams 1980). In 1935, Shmalgausen was appointed Director of the Institute of Evolutionary Morphology in Moscow, and for the next 10 years he focused on aspects of the theory of evolution as later set out in his book entitled: Factors of Evolution: The Theory of Stabilizing Selection.

As Scott Gilbert (2002, p. 206) notes: "Schmalhausen's landmark volume Factors of Evolution is nothing less than an attempt to integrate evolutionary morphology, population genetics, experimental embryology, and ecology into a coherent framework to provide a causal theory for evolution. This book places strong emphasis on what Schmalhausen called "dependent morphogenesis" (i.e., that part of development which depends on its environmental context) and the norms of reaction."

At this point, I would like to briefly emphasize one key issue of Shmalgausen's concept of "stabilizing" selection apparently tied to the evolution of development. It should be mentioned that this problem guided Shmalgausen's research throughout his professional life. His principal ideas on this type of selection were published in 1941. Five years later, Shmalgausen again comments on the concept of "stabilizing" selection in his Factors of Evolution (1946). In the 1950s, he prepared a manuscript specially dedicated to a role of "stabilizing" selection in development and 
evolution. This draft entitled "The stabilizing selection and evolution of individual development" was only published after his death (in 1982).

In this paper, Shmalgausen provided a precise account of his understanding of the role of "stabilizing" selection in ontogenesis and phylogenesis and stated conclusively that (1982, p. 367):

"Stabilizing selection is based on elimination of both heritable and non-heritable deviations from the adaptive norm. Thus, its result - a growing stability of the formshaping process - is related to changes of both internal and external factors of development."

It is usually noted that Shmalgausen's "stabilizing" selection would result in the "autonomization" of development and, in turn, the independence of development from external influences, whereas Shmalgausen himself suggested that "stabilizing" selection would lead to a lesser dependence of development on accidental environmental changes. "Neutral" variations of development, which do not disturb pattern formation and viability, could be fixed and further intensified by natural selection. Consequently, he concluded that (1982, p. 370-371):

"The continuously ongoing process of the accumulation of "neutral" mutations, keeping within the limits of the settled definitive norm, leads to a steady transformation of genotype, e.g., of the internal factors of development, and thereby it is bound up with a continually ongoing process of evolution of ontogenesis [.....]. A stabilization of concrete adaptive modifications is realized by a gradual substitution (in the course of accumulation of coincident mutations) of both external and functional factors of development by the internal ones."

In this sense, Shmalgausen's hypothesis of the "stabilization" of adaptive modifications via "gradual changes" in the genetic program of development is distinct from Waddington's concept of "canalization" which, in Waddington's own words, is that: “..... developmental reactions, as they occur in organisms submitted to natural selection, are in general canalized. That is to say, they are adjusted so as to bring about one definitive end-result regardless of minor variations in conditions during the course of the reaction" (Waddington 1942, p. 563).

Formally viewed, Waddington's canalization, buffering the developmental expression of genetic (and environmental) modifications, suggests a phenotypic stabilization of species and reduced evolution. Conversely, Shmalgausen's "stabilizing" selection of genetic (and environmental) modifications of development suggest (although not always with requisite significance) enhanced phenotypic variation within populations (Ellison et al. 2011).4 Despite a number of experimental efforts and computer simulation studies over the years, the concrete mechanisms underlying both "stabilizing" selection and canalization still remain elusive (but with certain progress, see Specchia et al. 2010).

Shmalgausen had a great capacity for synthesis and proposed epigenetic mechanisms for evolutionary innovation via changes in developmental systems. In doing this, he focused on theoretical considerations using the available data of comparative morphology, experimental embryology, population genetics, and ecology. In the early-mid 20th century such an approach, based largely on theoretical analysis rather than on experimental manipulations, was widely accepted not only in, but also outside Russia. In the 1990s, it became evident, however, that: "The study of the role of development in evolution must shift from a focus on theoretical considerations to the framing of experimental questions that can reveal mechanisms by which developmental processes influence evolutionary change" (Raff 1992, p. 16). The gradually emerging "evo-devo" trend, with novel experimental strategies to study the relationships between ontogenetic and phylogenetic changes in morphological characters, resulted in reinterpretation of morphological evolution in the terms of regulation of developmental key genes (Carroll 2008) and rearrangement of developmental gene regulatory networks (Davidson 2010). This, in turn, requires comparative studies of gene regulation networks in nonmodel organisms in an evolutionary context. 
There is a final point that I wish to make: the trend toward an approach rooted in comparative evolutionary embryology established by Kowalevsky and Mechnikoff before 1900, continued to be effective in Russia throughout the 20th century. In the second half of the 20th century, when much of developmental biology had been focused on model systems and developmental genetics, research at the St. Petersburg (Leningrad) State University in this field comparative and evolutionary embryology still continued, in great part due to the initiatives and efforts of Olga M. Ivanova-Kazas, Archil K. Dondua, and their students. The study of developmental patterns in representatives of major and minor phyla of invertebrates with an evolutionary perspective (see Ivanova-Kazas 1995; Dondua et al. 1997) challenged the selection of nonmodel organisms (Kulakova et al. 2007, 2008; Ereskovsky et al. 2009) paving the way for promising current "evodevo" research.

\section{Acknowledgments}

I am grateful to Alexander V. Ereskovsky who has motivated me to write this short account. I would like to specially acknowledge Scott F. Gilbert for his critical reading of the manuscript and Mario Torrado for help in the preparation of the figures. The work of the A.T.M. group is supported by a grant (SAF2008-00337) from the Spanish Ministry of Science and Innovation and by a grant (08CSA008161PR) from the Autonomous Government of Galicia.

1. The spelling of the proper names of the scientists is according to the system of transliteration officially established in Russia. An alternative spelling utilized in German and English publications is specified in the text.

2. This, and all subsequent quotations taken from Objecta Meditationum pro Theoria Monstrorum as well as quotations taken from the papers by Severtsov (1939, 1945), Golubovsky (2008), and Shmalgausen (1982) have been translated into English from Russian editions by this author.

3. Discussion of Severtsov's ideas on evolutionary comparative morphology anatomy (reviewed in Adams 1980; Levit et al. 2004; Levit 2007; Olsson et al. 2010) is outside the purpose and scope of the present article.

4. For more detailed commentary on both Shmalgausen's and Waddington's concepts, see Gilbert 2000, 2003; Hall 2003; Flatt 2005; Olsson et al. 2010.

\section{REFERENCES}

Adams, M. B. 1980. Severtsov and Schmalhausen: Russian morphology and the evolutionary synthesis. In E. Mayr and W. B. Provine (eds.). The Evolutionary Synthesis: Perspectives on the Unification of Biology. Harvard University Press, Cambridge.

Adams, M. B. 1988. Review: a missing link in the evolutionary synthesis. Isis 79: 281-284.

Baer, K. E.(M.) von. 1828 [1950]. History of Animal Development. Observations and Reflections. E. N. Pavlovsky (ed.), USSR Acad. Sci. ("Nauka") Press, Moscow (in Russian).

Baer, K. E. von. 1875 [1993]. Von Baer to Dohrn, 8/20 February 1875, Dorpat. In C. Groeben (ed.). Karl Ernst von Baer [1792-1876], Anton Dohrn [1840-1909]: Correspondence. Trans. Am. Philos. Soc. 83: 77.

Baer, K. E. von. 1886 [1986]. Autobiography of Dr. Karl Ernstvon Baer. In J. M. Oppenheimer (ed.). Science History Publcations, Canton, MA.

Barry, M. 1837. Further observations on the unity of structure in the animal kingdom and congenital anomalies including "hermaphrodites", with some remarks on embryology as facilitating animal nomenclature, classification, and the study of comparative anatomy. Edinburgh New Philos. J. 22: 345364.

Blyakher, L. Ya. 1955 [1982]. History of Embryology in Russia from the Middle of the XVIII to the Middle of the XIX Century The Al Ahram Center for Sci. Transl., Washington.

Bowler, P. J. 1996. Life's Splendid Drama: Evolutionary Biology and the Reconstruction of Life's Ancestry, 1860-1940. D. L. Hull (ed.). Universityof Chicago Press, Chicago.

Brauckmann, S. 2008. The many spaces of Karl Ernst von Baer. Biol. Theory 3: 85-89.

Brauckmann, S., and Gilbert, S. F. 2004. Sucking in the gut: a brief history of early studies on gastrulation. In C. D. Stern (ed.). Gastrulation. Cold Spring Harbor Press, Cold Spring Harbor.

Breidbach, O., and Ghiselin, M. 2007. Evolution and development: past, present, and future. Theory Biosci. 125: $157-171$. 
Carroll, S. B. 2005. Endless Forms Most Beautiful: The New Science of Evo Devo and the Making of the Animal Kingdom. W. W. Norton \& Company, New York.

Carroll, S. B. 2008. Evo-devo and an expanding evolutionary synthesis: A genetic theory of morphological evolution. Cell 134: 25-36.

Davidson, E. H. 2010. Emerging properties of animal regulatory networks. Nature 468: 911-920.

Delsuc, F., Brinkmann, H., Choumout, D., and Philippe, H. 2006. Tunicates and not cephalochordates are the closet living relatives of vertebrates. Nature 439: 965-968.

Dettlaff, T. A., and Vassetzky, S. G. 1997. Experimental embryology in Soviet Russia: the case of Dmitrii P. Filatov. Int. J. Dev. Biol. 41: 781-787.

Domazet-Lošo, T., and Tautz, D. 2010. A phylogenetically based transcriptome age index mirrors ontogenetic divergence patterns. Nature 468: 815-818.

Dondua, A. K., Kostyuchenko, R. P., and Fedorova, Z. E. 1997. Effects of some cytoskeleton inhibitors on ooplasmic segregation in the Nereis virens egg. Int. J. Dev. Biol. 41: 853-858.

Dumont, J.-C. 2007. Pre-Kantian revival of epigenesis: Caspar Friedrich Wolff's "De formation intestine..um (1768-69). In P. Huneman (ed.). Understanding Purpose. Kant and the Philosophy of Biology. Universityof Rochester Press, Rochester.

Ellison, C. K., Wiley, C., and Shaw, K. L. 2011. The genetics of speciation: genes of small effect underlie sexual isolation in the Hawaiian cricket Laupala. J. Evol. Biol. 24: 1110-1119.

Ereskovsky, A. V., et al. 2009. The Homoscleromorph sponge Oscarella lobularis, a promising sponge model in evolutionary and developmental biology. BioEssays 31: 89-97.

Filatov, D. P. 1939. The Comparative-Morphological Trend in Developmental Mechanics. Its Object, Aims and Methods. USSR Acad. Sci. ("Nauka") Press, Moscow-Leningrad (in Russian).

Filatov, D. P. 1941. The historical approach to the phenomena of developmental mechanics and its significance. J. Gen. Biol. 2: 3-16 (in Russian).

Flatt, T. 2005. The evolutionary genetics of canalization. Q. Rev. Biol. 80: 287-316.

Gaissinovitch, A. E. 1990. C. F. Wolff on variability and heredity. Hist. Philos. Life Sci. 12: 179-201.

Gilbert, S. F. 2000. Diachronic biology meets evo-devo: C. H. Waddington's approach to evolutionary developmental biology. Am. Zool. 40: 729-737.

Gilbert, S. F. 2002. The genome in its ecological context. Philosophical perspectives on interspecies epigenetics. Ann. N. Y. Acad. Sci. 981: 202-218.

Gilbert, S. F. 2003. The morphogenesis of evolutionary developmental biology. Int. J. Dev. Biol. 47: 467477.

Gilbert, S. F., and Epel, D. 2009. A Review of Ecological Developmental Biology: Integrating Epigenetics, Medicine, and Evolution. Sinauer Ass., Sunderland, MA.

Golubovsky, M. D. 2008. Valentin Sergeevich Kirpichnikov: to the 100th anniversary of his birth (19081991). VOGiS Herald, 12: 281-288 (in Russian).

Gourko, H., Williamson, D. I., and Tauber, A. I. (eds.). 2000. The Evolutionary Biology Papers of Elie Metchnikoff. Kluwer Acad. Publ., Dordrecht.

Hall, B. K. 1997. Phylotypic stage or phantom: is there a highly conserved embryonic stage in vertebrates? TREE 12: 461-463.

Hall, B. K. 1999. Evolutionary Developmental Biology. Kluwer Acad. Publ., Dordrecht.

Hall, B. K. 2003. Baldwin and beyond: organic selection and genetic assimilation. In: B. H. Weber and D. J. Depew (eds.). Evolution and Learning. The Baldwin Effect Reconsidered. MIT Press, Cambridge, MA.

Hoßfeld, U., and Olsson, L. 2003. The road from Haeckel: The Jena tradition in evolutionary morphology and the origins of "Evo-Devo". Biol. Philos. 18: 285-307.

Ivanova-Kazas, O. M. 1992. Baer's law of ontogenic divergence. Ontogenez (Russ. J. Dev. Biol.) 23: 175179 (in Russian).

Ivanova-Kazas, O. M. 1995. Evolutionary Embryology of Animals. Russ. Acad. Sci. (“Nauka”) Press, St. Petersburg (in Russian).

Kalinka, A. T., et al. 2010. Gene expression divergence recapitulates the developmental hourglass model. Nature 468: 811-814.

Kulakova, M., et al. 2007. Hox gene expression in larval development of the polychaetes Nereis virens and Platynereis dumerilii (Annelida, Lophotrochozoa). Dev. Genes Evol. 217: 39-54.

Kulakova, M. A., Cook, C. E., and Andreeva, T. F. 2008. ParaHox gene expression in larval and postlarval development of the polychaete Nereis virens (Annelida, Lophotrochozoa). BMC Dev. Biol. 8: 61-71.

Kirpichnikov, V. S. 1935. The role of non-hereditary variability in the process of natural selection (indirect selection hypothesis). Biol. J. 4: 775-800 (in Russian).

Kirpichnikov, V. S. 1947. The problem of non-hereditary adaptive modifications (coincident or organic selection). J. Genet. 48: 164-175.

Lemaire, P., Smith, W. C., and Hishida, H. 2008. Ascidians and the plasticity of the chordate developmental program. Curr. Biol. 18: 620-631.

Levit, G. S. 2007. The roots of evo-devo in Russia: is there a characteristic "Russian tradition"? Theory Biosci. 126: 131-148. 
Levit, G. S., Hossfeld, U., and Olsson, L. 2004. The integration of Darwinism and evolutionary morphology: Alexej Nikolajevich Sewertzoff (1866-1936) and the developmental basis of evolutionary change. J. exp. Zool. (Mol. Dev. Evol.) 302B: 343-354.

Levit, G. S., Hossfeld, U., and Olsson, L. 2006. From the 'modern synthesis' to cybernetics: Ivan Ivanovich Schmalhausen (1884-1963) and his research program for a synthesis of evolutionary and developmental biology. J. Exp. Zool. 306B: 89-106.

Lukina, T. A. (ed.). 1973. Caspari Friderici Wolffii: Objecta Meditationum pro Theoria Monstrorum. USSR Acad. Sci. ("Nauka") Press, Leningrad (in Latin and Russian).

Lukina, T. A. 1978. From Epistolary Heritage ofK. M. Baer in European Archives. USSR Acad. Sci. ("Nauka") Press, Leningrad (in Russian).

Mikhailov, A. T. 1997. Epigenesis versus preformation: first chapter of the Russian embryological research. Int. J. Dev. Biol. 41: 755-762.

Mikhailov, A. T., and Gorgolyuk, N. A. 2001. Consequences of the Spemann-Mangold organizer concept for embryological research in Russia: personal impressions. Int. J. Dev. Biol. 45: 83-96.

Mikhailov, A. T., and Gilbert, S. F. 2002. From development to evolution: the re-establishment of the “Alexander Kowalevsky Medal”. Int. J. Dev. Biol. 46: 693-698.

Oppenheimer, J. M. 1963. K. E.von Baer's beginning insights into causal-analytical relationships during development. Dev. Biol. 7: 11-21.

Ospovat, D. 1976. The influence of Karl Ernst von Baer's embryology, 1828-1859: A reappraisal in the light of Richard Owen's and William B. Carpenter's paleontological application of von Baer's law. J. Hist. Biol. 9: $1-28$.

Okada, T. 2000. Lens studies continue to provide landmarks of embryology (developmental biology). J. Biosci. 25: 133-141.

Olsson, L., Levit, G. S., and Hoßfeld, U. 2010. Evolutionary developmental biology: its concepts and history with focus on Russian and German contributions. Naturwissenschaften 97: 951-969.

Piliptchuk, O. J. 2003. A. O. Kowalevsky. Russ. Acad. Sci. ("Nauka") Press, Moscow (in Russian).

Raff, R. A. 1992. Evolution of developmental decisions and morphogenesis: the view from two camps. Development Suppl:: 15-22.

Raff, R. A. 1996. The Shape of Life: Genes, Development, and the Evolution of Animal Form. University of Chicago Press, Chicago.

Raff, R. A., and Love, A. C. 2004. Kowalevsky, comparative evolutionary embryology, and the intellectual lineage of evo-devo. J. Exp. Zool. (Mol. Dev. Evol.) 302B: 19-34.

Raineri, M. 2009. On some historical and theoretical foundations of the concept of chordates. Theory Biosci. 128: 53-73.

Raykov, B. E. 1964. Caspar Friedrich Wolff. Zool. Jahrbücher, Systematik, Ökologie und Geographie 91: 555-626.

Richards, R. J. 1992. The Meaning of Evolution. The morphological construction and ideological reconstruction of Darwin's theory. University of Chicago Press, Chicago.

Roe, S. A. 1979. Rationalism and embryology: Caspar Friedrich Wolff's theory of epigenesis. J. Hist. Biol. 12: $1-43$.

Schierwater, B., et al. 2009. Concatenated analysis sheds light on early metazoan evolution and fuels a modern "urmetazoon" hypothesis. PloS Biol. 7: e1000020. doi:10.1371/journal.pbio.100002000.

Schmitt, S. 2005. From eggs to fossils: epigenesis and transformation of species in Pander's biology. Int. J. Dev. Biol. 49: 1-8.

Severtsov, A. N. 1939. The Morphological Regularities of Evolution. USSR Acad. Sci. ("Nauka") Press, Moscow-Leningrad (in Russian).

Severtsov, A. N. 1945. Models of phylembryogenesis. In: Collected Works (vol. 3). USSR Acad. Sci. ("Nauka") Press, Moscow-Leningrad (in Russian).

Shmalgausen, I. I. 1946. Factors of Evolution: The Theory of Stabilizing Selection, USSR Acad. Sci. ("Nauka") Press, Moscow-Leningrad. (1949, Engl. transl. ed. by T. Dobzhansky, Chicago Univ. Press, Chicago and London; 2010, German transl. ed. by U. Hossfeld, L. Olsson, G. S. Levit, and O. Breidbach, Franz Steiner Verlag, Stuttgart).

Shmalgausen, I. I. 1982. Stabilizing selection and evolution of individual development. In E. I. Vorob'eva and I. M. Medvedeva (eds.). Selected Works: The Organism as a Whole in Individual and Historical Development. USSR Acad. Sci. ("Nauka") Press, Moscow.

Specchia, V., et al. 2010. Hsp90 prevents phenotypic variation by suppressing the mutagenic activity of transposons. Nature 463: 662-665.

Tauber, A. I. 1990. Metchnikoff, the modern immunologist. J. Leukocyte Biol. 47: 561-567.

Tauber, A. I. 2003. Metchnikoff and the phagocytosis theory. Nature Rev.Mol. Cell. Biol. 4: 897-901.

Vorob'eva, E. I. 2010. Evo-devo and the I. I. Schmalhausen concept of the evolution of ontogeny. Biol. Bull. 37: 106-113.

Vucinich, A. 1988. Darwin in Russian Thought. University of California Press, Berkeley and Los Angeles.

Waddington, C. H. 1942. Canalization of development and the inheritance of acquired characters. Nature 150: $563-565$ 
Witt, E. 2008. Form - a matter of generation: the relation of generation, form, and function in the epigenetic theory of Caspar F. Wolff. Sci. Context. 21: 649-64.

Yamamoto, Y., and Jeffery, W. R. 2000. Central role for the lens in cave fish eye degeneration. Science 289: 631-633. 